\title{
Pathologic Stage IIIA Gastric Cancer AJCC v8
}

National Cancer Institute

\section{Source}

National Cancer Institute. Pathologic Stage IIIA Gastric Cancer A/CC v8. NCI Thesaurus. Code $C 133665$.

Stage IIIA includes: (T2, N3a, M0); (T3, N2, M0); (T4a, N1, M0); (T4a, N2, M0); (T4b, N0, M0). T2: Tumor invades the muscularis propria. T3: Tumor penetrates the subserosal connective tissue without invasion of the visceral peritoneum or adjacent structures. T4a: Tumor invades the serosa (visceral peritoneum). T4b: Tumor invades adjacent structures/organs. N0: No regional lymph node metastasis. N1: T umor with metastasis in one or two regional lymph nodes. N2: Tumor with metastasis in three to six regional lymph nodes. N3a: T umor with metastasis in seven to fifteen regional lymph nodes. M0: No distant metastasis. (AJCC 8th ed.) 